\title{
INSTITUCIONES EDUCATIVAS \\ CONFESIONALES Y EL IMPACTO \\ EN EL DESARROLLO LOCAL: el caso \\ de la Universidad Adventista del Plata \\ (UAP) en la Ciudad del Libertador San Martin (ARGENTINA)
}

\author{
RICARDO COSTA CAGGY \\ Universidad Adventista del Plata (UAP). Doutor em Administração pela Universidade \\ Federal da Bahia - UFBA (2018). Mestre em Gestão, Planejamento e Estratégia \\ Empresarial pela Universidade Autônoma de Lisboa (2006), Mestre em Administração \\ pela Universidade Federal da Bahia (2011). Especialista em Docência do ensino \\ superior pela Faculdade Adventista de Educação do Nordeste - FAENE (2006). \\ ORCID: 0000-0002-8188-2708; E-mail: ricardocostacaggy@gmail.com
}




\section{INSTITUCIONES EDUCATIVAS CONFESIONALES Y EL IMPACTO EN EL DESARROLLO LOCAL: el caso de la Universidad Adventista del Plata (UAP) en la Ciudad del Libertador San Martin (ARGENTINA)}

Las instituciones educativas confesionales siempre han desempeñado un papel relevante en la sociedad, en el proceso de formación y producción de conocimiento. Por otro lado, la producción académica reciente sobre el impacto de las instituciones educativas en el proceso de desarrollo local se ha centrado principalmente en las contribuciones de las universidades públicas y / o de los grandes conglomerados educativos. Este estudio tuvo como objetivo analizar el impacto producido por una institución educativa confesional en el proceso de desarrollo de una ciudad. El análisis del contenido de las entrevistas realizadas con los actores sociales de la comunidad y los gerentes universitarios se utilizó para comparar los discursos e inferir sobre las diferentes dimensiones del impacto de estas organizaciones. Al final se dio cuenta de que, además de los impactos ya consolidados en la literatura (económica, del conocimiento y social), las instituciones también pueden impactar en la construcción del territorio y el sistema simbólico cultural. En el caso bajo análisis, el proceso de desarrollo de la comunidad se lleva a cabo en paralelo con el proceso de desarrollo de la institución en un modelo basado en las premisas filosóficas de la institución, lo que demuestra el poder que las organizaciones tienen en la construcción de la cultura simbólica y local.

Palabra clave: Instituciones educativas confesionales. Educación superior. Desarrollo local.

\section{THE CONFESSIONAL EDUCATIONAL INSTITUTIONS AND THE IMPACT ON LOCAL DEVELOPMENT: the case of the Universidad Adventista Del Plata (UAP), at the city Liberador San Martin (ARGENTINA)}

The Confessional Institutions of teaching have always played a relevant role in society, in the process of formation and production of knowledge. On the other hand, the recent academic production regarding the impact of educational institutions on the local development process has been mainly concerned with the contributions of public universities and large educational conglomerates. This study aimed to analyze the impact produced by a denominational teaching institution in the process of developing a city. It was used the analysis of the content of interviews conducted with community social actors and university managers to compare the discourses and infer about the different dimensions of the impact of these organizations. It was realized at the end that in addition to the impacts already consolidated in the literature (economic, knowledge, and social) institutions can also impact the construction of the territory and the symbolic cultural system. In the case under analysis, the process of community development occurs in parallel with the institution's development process in a model based on the philosophical premises of the institution demonstrating the power that organizations have in the construction of the symbolic and local culture.

Keywords: Moral Development. Confessional Institutions of Education. Higher Education.

\section{plurais}




\section{INSTIUIÇÕES EDUCATIVAS CONFESSIONAIS E O IMPACTO NO DESENVOLVIMENTO \\ LOCAL: o caso da Universidad Adventista del Plata (UAP) na cidade Libertador San Martin (ARGENTINA)}

As instituições confessionais de Educação sempre desempenharam um papel relevante na sociedade e no processo de formação e produção de conhecimento. Por outro lado, a produção acadêmica recente, sobre o impacto das instituições educacionais no processo de desenvolvimento local, está basicamente centrada nas contribuições das universidades publicas e/ou nos grandes conglomerados educativos privados. Este estudo teve como objetivo analisar o impacto produzido por uma instituição confessional de educação no processo de desenvolvimento de uma cidade. A análise do conteúdo das entrevistas realizadas, com os atores sociais da comunidade e os dirigentes da universidade, comparou os discursos e permitiu reflexões sobre as diferentes dimensões do impacto destas organizações. Em conclusão se percebeu que, além dos impactos tradicionalmente apresentados na literatura (econômico, conhecimento e social), as instituições também podem impactar na construção do território e no sistema simbólico cultural. No caso em análise o processo de desenvolvimento da comunidade está vinculado com o processo de desenvolvimento da instituição, em um modelo baseado nas premissas filosóficas das instituições, demonstrando o poder das organizações na construção cultural e simbólica do local.

Palavras-chave: Instituições Confessionais de Educação. Educação Superior. Impacto. Desenvolvimento Local. 


\section{INSTITUCIONES EDUCATIVAS CONFESIONALES Y EL IMPACTO EN EL DESARROLLO LOCAL: el caso de la Universidad Adventista del Plata (UAP) en la Ciudad del Libertador San Martin (ARGENTINA)}

\section{Introducción}

Generalmente se evalúan las instituciones de educación superior (IES) por sus contribuciones en el proceso de formación de capital humano y por el desarrollo de la ciencia y el progreso tecnológico. Sin embargo, en los últimos años, el número de publicaciones que demuestran otras contribuciones de estas organizaciones, además del alcance educativo, ha ido en aumento.

La capacidad económica de estas organizaciones y el impacto producido en las ciudades en las que están instaladas (ELLIOTT; LEVIN; MEISEL, 1988; BLUESTONE, 1993; ROLIM; KURESKI, 2010; MADER et al., 2013), la capacidad de mejorar el capital intelectual, la actividad emprendedora, los sistemas de innovación, la interacción con gobiernos y empresas, y los mecanismos de sostenibilidad en las regiones son objeto de diferentes estudios que buscan evaluar las contribuciones de las IES más allá de la lógica económica (ETZKOWITZ; LEYDESDORFF, 1997; BLACKWELL; COBB; WEINBERG, 2002; GARRIDO-YSERTE; GALLO-RIVERA, 2008).

De esta manera, estas organizaciones pueden desempeñar papeles cruciales en términos de estrategias de desarrollo local, superando los modelos tradicionales de desarrollo, que están basados en la inversión extranjera en la región, y creando posibilidades de aumento de las capacidades locales y aprovechamiento de los recursos regionales. En este artículo, la propuesta es un análisis del impacto de una institución de educación superior en el desarrollo de una localidad, buscando identificar los efectos cualitativos de esta institución en diferentes perspectivas de desarrollo, a través de una visión interdisciplinaria y multiparadigmática para la interpretación de los datos.

La pregunta guía del estudio es comprender el impacto que una IES (en el caso la Universidad Adventista del Plata - UAP), como institución educativa confesional (IEC), tiene en el desarrollo de una ubicación específica (Libertador San Martín, Entre Ríos, Argentina). En este trabajo, el factor cultural y el proceso de desarrollo de la educación superior se agrega en una realidad diferente a de 
Brasil, proporcionando subsidios para futuros análisis y comparaciones sobre el impacto de estas IES en el proceso de desarrollo local.

El presente trabajo seguirá una estructura de presentación de las bases teóricas para el análisis del caso; luego las estructuras metodológicas que permitieron realizar la investigación y el análisis; la tercera parte con el estudio de caso en sí, y finalmente se presentan las consideraciones finales, limitaciones y recomendaciones futuras para investigaciones similares.

\section{Bases Teóricas}

Los cambios sociales que han ocurrido en los últimos 30 años en la sociedad han demostrado la fuerza que el conocimiento, la información y la tecnología tienen como vectores de cambios significativos en la sociedad. Si aún no es posible afirmar que existe una "sociedad del conocimiento", no hay duda de que el poder del conocimiento es el principal generador de cambios de las últimas tres décadas.

Es dentro de este contexto, que las universidades surgen como uno de los principales actores en este proceso de producción y difusión del conocimiento científico, adquiriendo un papel único con respecto al proceso de desarrollo de las regiones y facilitando la creación de un entorno favorable a la innovación y ventajas competitivas. regiones (SIQUEIRA; FERRAZ, 2016).

Los estudios iniciales sobre el impacto de las IES en el proceso de desarrollo de las regiones dirigieron su análisis a los factores económicos que contribuyen a la existencia de estas organizaciones en la región, como la creación de empleo, el gasto de estudiantes, docentes y universidades de la región, dinero disponible en la región, aumentos de impuestos y el grado de emprendimiento generado en la región debido a la existencia de estas organizaciones (ELLIOTT; LEVIN; MEISEL, 1988; BLUESTONE, 1993; ROLIM; SERRA, 2009; ROLIM; KURESKI, 2010; PASTOR; PÉREZ; GUEVARA, 2013; ROLIM; SERRA; BASTOS, 2014). Estos estudios se caracterizaron como estudios de impacto a corto plazo o estudios de impacto bajo demanda.

Por otro lado, estudios más recientes buscaron identificar otros efectos que la presencia de IES genera en sus territorios, como la mejora del capital humano local, la relación de las IES con empresas e industrias de la región, la atracción de nuevas empresas, el formación de líderes locales, mejora en el proceso de gobernanza de las ciudades, la creación de sistemas regionales de 
innovación, el proceso de valorización cultural y el despertar de las regiones a las preocupaciones ambientales (BLUESTONE, 1993; ETZKOWITZ; LEYDESDORFF, 1997; LESTER; SOTARAUTA, 2007; GARRIDO-YSERTE; GALLO-RIVERA, 2008; SUPRIYADI, 2012; MADER et al., 2013; SHIKIDA et al., 2015). Estos análisis están relacionados con los llamados efectos en el lado de la oferta, o los efectos a largo plazo de la presencia de universidades en ciertas regiones.

El uso creciente de estudios en esta área demuestra la importancia de la contribución de estas instituciones en el desarrollo de ciudades y regiones, en su estudio, Arbo y Benneworth, (2007) señalan como contribuciones perceptibles:

Una de las principales conclusiones de esta investigación es el alcance de la interacción entre los diversos impactos sectoriales de las universidades. Existen vínculos claros entre innovación y enseñanza, enseñanza y gobernanza, desarrollo sostenible e investigación / enseñanza. Las universidades han sido capaces de reunir y utilizar diferentes áreas de conocimiento. Las primeras instituciones religiosas utilizaron los recursos de las órdenes religiosas como un medio para proporcionar una oportunidad para el trabajo académico, que, a su vez, se transmitió a través de la enseñanza. Las universidades de Wilhelminian tenían como objetivo producir un impacto industrial transformador, precisamente combinando la enseñanza y la investigación con un fuerte enfoque en la aplicabilidad industrial. Hasta cierto punto, una mayor conciencia del valor de las universidades es consecuencia de un aumento en la escala de estas actividades. Si bien la educación superior en la década de 1960 podría haber sido una actividad de élite, ahora es un sector que está estrechamente relacionado con gran parte de la sociedad. La creciente importancia del conocimiento y los problemas para aquellos que están excluidos de las sociedades del conocimiento ha hecho de las universidades y el acceso a ellas un tema social clave (ARBO; BENNEWORTH, 2007, p. 55).

A pesar de esta innegable contribución de las instituciones educativas en el desarrollo de las regiones, todavía es necesario un largo trabajo para que esto suceda de manera intencional y planificada por todas las IES. Algunos de ellas están más preocupados por cuestiones de conocimiento universal y temas de debate nacional, sin mirar el lugar donde están instalados.

Esta perspectiva de desempeño está sujeta a la diferenciación de la clasificación de la universidad por Rolim y Serra (2010) en lo que llaman "ser y estar" en la región. Para los autores, las IES que "son" de la región, investigan temas regionales, capacitan a las personas para la región y

\section{plupais}


buscan asociarse con otros actores de la región. Sin embargo, aquellos que "están" en la región, muestran dificultad para articularse localmente, tienen proyectos de desempeño e investigación con un enfoque nacional e internacional, sin preocuparse por las necesidades locales.

Esta diferenciación se debe a la perspectiva de desarrollo que se espera para la región y a la comprensión del concepto de desarrollo en sí mismo (por parte de los diferentes actores sociales involucrados en el proceso, ya sea dentro de la universidad o fuera de ella). La limitación de la perspectiva de desarrollo solo para factores económicos, es decir, una simple asociación con el crecimiento económico hace que sea imposible tener diferentes perspectivas con respecto al proceso de desarrollo, ampliando su comprensión a las dimensiones sociales, políticas, culturales, ambientales y territoriales (SEN, 1999; SACHS, 2004). Además, Boiser (1996) sugiere como metodología para el análisis del desarrollo regional la estructura de un hexágono, en el que el desarrollo de un territorio, de forma organizada, se produce en función de la articulación de seis elementos diferentes:

Figura 1. Hexágono de desarrollo regional

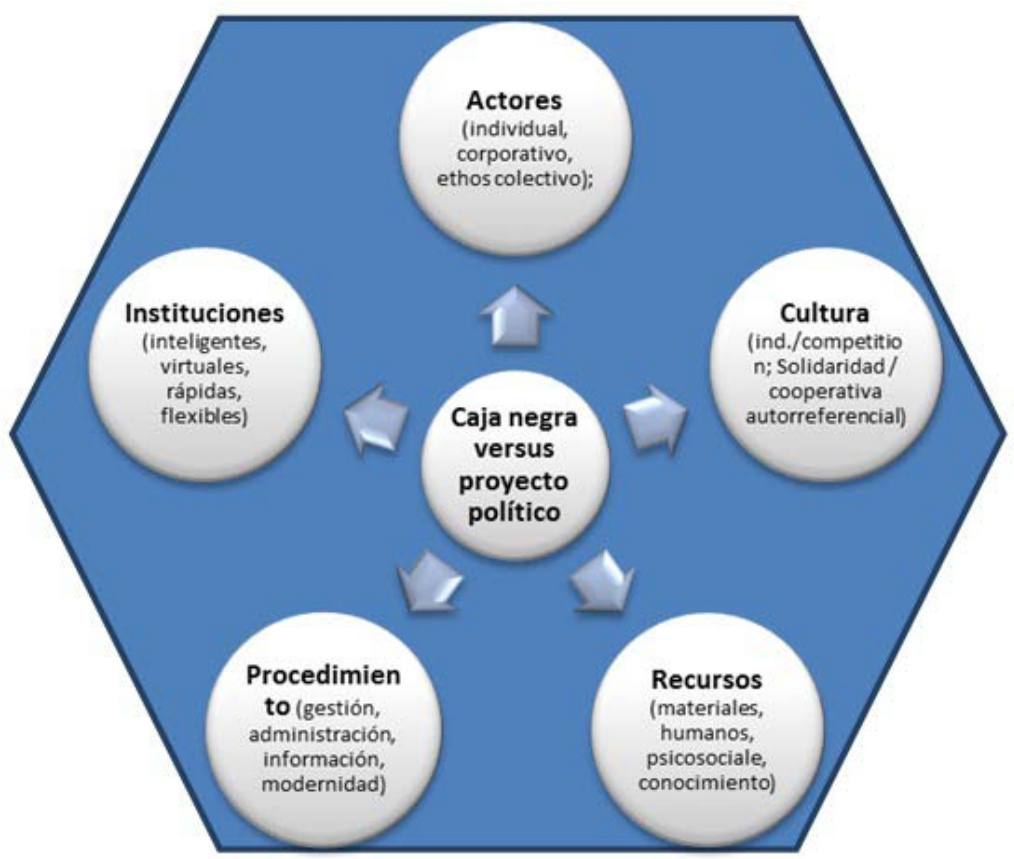

Fuente: Adaptado Boiser (1996)

\section{plurais}


De acuerdo con Boiser (1996), el desarrollo organizado de un territorio no depende solo de la existencia de los seis elementos, sino de su articulación. La tarea consiste en buscar mecanismos que faciliten el proceso de articulación de acuerdo con las necesidades y capacidades territoriales, buscando moldes que realmente interesen a la región, con la participación de actores sociales, la profesionalidad de la gestión pública y la producción de conocimiento para la región. A pesar de la simplificación conceptual, el modelo representa la necesidad de prestar atención a las cuestiones comerciales, políticas y de gestión de la tierra, aspectos que a menudo se pasan por alto en otros enfoques, especialmente cuando la atención se centra en atraer inversiones.

Este modelo es consistente con las perspectivas de desarrollo endógeno relacionadas con el aumento de las capacidades locales y el respeto por los recursos locales. Se hace hincapié en la acción colectiva para el uso de los recursos locales, el empoderamiento institucional y la cooperación en red, teniendo en cuenta las necesidades humanas locales, involucrando a la comunidad y utilizando y aplicando principios de sostenibilidad (SUPRIYADI, 2012).

En este sentido, la perspectiva más alineada con este trabajo se encuentra en el trabajo de Celso Furtado, en el que el autor considera que el proceso de desarrollo "es principalmente un proceso de activación y canalización de fuerzas sociales, avance en capacidad asociativa, ejercicio de iniciativa e inventiva. Por lo tanto, es un proceso social y cultural, y solo secundariamente económico" (FURTADO, 1982, p. 149).

En este sentido, es importante resaltar la influencia de otros dos vectores en la composición de la estructura de análisis de este caso. El primero, con respecto a la comprensión del espacio o la ubicación, no solo como un espacio geográfico estático, sino como un espacio con una identidad (cultural, ambiental, social, económica y política), una dinámica y la influencia de sus diferentes actores que lo componen y relaciones intrínsecas con el tiempo, el mundo y el espacio físico (SANTOS, 1997; ZAPATA, 2007; HARVEY, 2012; SANTOS, 2014b; MADOERY, 2016).

El segundo vector es la comprensión de que, además de los problemas formales y visibles (planes de estudio, proyectos, acciones, investigación, extensión), las universidades son productoras de valores, ritos, creencias y sistemas de interpretación del mundo (DURKHEIM, 1996; WEBER, 1999; BOURDIEU, 2015), que influyen en la composición de una comunidad y su desempeño mo-

\author{
plupais


ral, comprensión de la ética y su desempeño en la vida cotidiana (RUSS; SARGENT, 2006; HILL, 2009; HANSON; MOORE, 2014; DAVIGNON; THOMSON JR., 2015; HANSON et al., 2017).

Estos dos vectores son fundamentales para el análisis propuesto en este estudio, considerando que las instituciones educativas tienen capacidades transformadoras y producen articulaciones para la formación de territorios, es decir, un espacio socialmente construido, a través de conflictos y confluencias, entre personas o grupos, y que tienen un fuerte carácter político e institucional, produciendo su propia identidad (FISCHER, 1991, 1997; HAESBAERT, 2005; ZAPATA, 2007; HAESBAERT, 2011; DOWBOR, 2016; MADOERY, 2016). Además, los impactos organizacionales no se limitan al campo económico, las organizaciones son responsables de la articulación entre lo local y lo global, el aislamiento o la articulación, la expansión o reducción de la participación social en los procesos de construcción, impactando así directamente la comprensión. del desarrollo previsto y aún más en la agenda de intereses de desarrollo (GOULART; VIEIRA, 2007, 2008).

Por lo tanto, la comprensión de esta compleja realidad debe entenderse desde los diferentes roles que tienen estas organizaciones, desde sus contribuciones y limitaciones en el desarrollo de los territorios.

\section{Indicaciones Metodológicas}

Los estudios sobre los impactos de las universidades en el proceso de desarrollo de las regiones se basan en sus propias metodologías e instrumentos consolidados en la literatura, con respecto a los impactos considerados a corto plazo. La mayoría de ellos están vinculados a la función económica de las IES y los análisis se llevan a cabo utilizando diferentes indicadores de la base económica, ya sea a través de la matriz de entrada-salida, en la matriz de contabilidad social, en el modelo de equilibrio general computable (EGC), o a través de modelos con multiplicadores keynesianos, el objetivo principal es presentar la contribución económica de la universidad a la región y realizar una comparación dentro de la economía local si la universidad no estaba instalada (ROLIM; KURESKI, 2010).

Otros estudios de base económica también tienen como objetivo utilizar el cociente de ubicación (QL) para identificar la existencia de centros de educación superior en regiones donde 
hay varias instituciones (LOPES, 2001, 2012; SIQUEIRA; FERRAZ, 2016) y el impacto de estos centros en la economía. ubicación

Como el propósito de este estudio es un análisis más allá de la dimensión económica, optamos por otro enfoque con respecto al análisis del impacto de la IES en el lugar donde se inserta, buscando evaluar no solo el impacto a corto plazo, pero también a largo plazo. La OCDE (Organización para la Cooperación y el Desarrollo Económico), a través del proyecto Spporting the Contribution of Higher Institutions to Regional Development (SCHEIRD), que se llevó a cabo entre 2004 y 2016, promovió una serie de estudios de esta naturaleza en todo el mundo. 30 casos en 23 países, en los cuales los principales temas investigados fueron: contribución de la investigación realizada en las IES a la innovación regional; contribución de la educación para aumentar la capacidad y servir al mercado laboral regional; contribución al desarrollo social, cultural y ambiental; creación de capacidad institucional para la cooperación regional; el papel de liderazgo y asociación de las IES en la comunidad regional; desarrollo de habilidades, emprendimiento e innovación; y el papel de las instituciones educativas y otros actores sociales en el proceso de desarrollo de ciudades y regiones de todo el mundo (OCDE / IMHE, 2005).

En general, estos estudios utilizaron la misma metodología para su desarrollo, compuesta de cinco fases: 1) Presentación del programa a actores regionales (IES, representantes del sector productivo, políticos, etc.); 2) recopilación de información de IES a través de un formulario de autodiagnóstico; 3) Visita de los coordinadores del proyecto a los actores regionales y realización de las entrevistas; 4) Realización de talleres con la participación de IES y actores regionales, para preparar un análisis utilizando la matriz DAFO (Oportunidades y Amenazas, Fortalezas y Debilidades); y 5) construcción del informe final para la visita de la comisión de la OCDE, que promueve el análisis y prepara contribuciones para el trabajo.

Para esta investigación, se buscó un enfoque metodológico con el trabajo de la OCDE, para lo cual se observó IES y sus alrededores in loco; seguido del diagnóstico a través de entrevistas (guion predefinido) con representantes de las IES y actores sociales locales; y finalmente el análisis documental de la IES. Además, se recopilaron datos de carácter secundario disponibles de diferentes fuentes gubernamentales para la composición del marco analítico. En este sentido, esta investigación se caracteriza por ser exploratoria, descriptiva, de naturaleza cualitativa. Se usó un estudio de caso único como estrategia de investigación, que se eligió intencionalmente y no pro-

\section{plupais


babilísticamente, así como el primer artículo de esta serie. Estas elecciones se justifican según los paradigmas epistemológicos adoptados, siendo el constructivista, funcionalista (postpositivista) y las aportaciones de la complejidad.

Los datos recopilados se analizaron a partir de categorías preestablecidas y el método de análisis de contenido se utilizó para codificar las entrevistas. Estas elecciones metodológicas fueron las más apropiadas, dadas las limitaciones del acceso a la información; la naturaleza del objeto de análisis; porque es un fenómeno que no puede separarse de su contexto; la necesidad de dialogar con otras disciplinas para comprender el todo; y la necesidad de triangular diferentes fuentes para comprender el objeto (YIN, 2005; VASCONCELOS, 2007; CRESWELL, 2010; BARDIN, 2011).

Las categorías de análisis propuestas para este trabajo fueron: la dimensión económica, la dimensión del conocimiento, la dimensión social, la dimensión territorial / ambiental y la dimensión cultural. Todas las entrevistas fueron transcritas y sometidas a análisis utilizando Nvivo11, para identificar las categorías, se definieron los "nodos" de codificación para el caso. Las unidades de registro elegidas para el análisis fueron el tema, o el recorte, (enunciado sobre un tema, una oración o una oración compuesta), que se utiliza para estudiar opiniones, valores, creencias y actitudes con el objetivo de categorizar y contar frecuencia (BARDIN, 2011).

Además de las categorías de análisis predefinidas, se crearon seis nodos adicionales durante el análisis (positivo, negativo, fortaleza, debilidad, oportunidad y amenaza). El objetivo era identificar en el contenido de las entrevistas la percepción de los entrevistados sobre los impactos positivos y negativos, así como la posibilidad de construir una matriz DAFO en el análisis, como lo sugieren los estudios promovidos por la OCDE (OCDE / IMHE, 2005).

Para realizar las entrevistas, se eligieron 13 actores sociales, de los cuales 7 eran residentes y / o empresarios del lugar y se identificarán en las entrevistas como ATOR01, ATOR02, ATOR03, ATOR04, ATOR05, ATOR06 y ATOR07 y 6 gerentes de la institución (el decano de la universidad, decano académico, director de ciencia y tecnología, decano del departamento de salud, decano del departamento de ciencias sociales aplicadas y director de responsabilidad social) todos serán identificados como PROFESOR-ARGENTINA1, 2, 3, 4, 5, 6 y 7 (PA1, PA2, ...). Además de estas entrevistas, se realizó una entrevista adicional con el director de educación de la red de educación adventista para América Latina, que se identificará en esta investigación como DAS. 
La generación del mapa de análisis de contenido a través de Nvivo11 presenta la relación entre las categorías de análisis y las entrevistas realizadas:

Figura 2- Mapa del análisis del contenido de las entrevistas

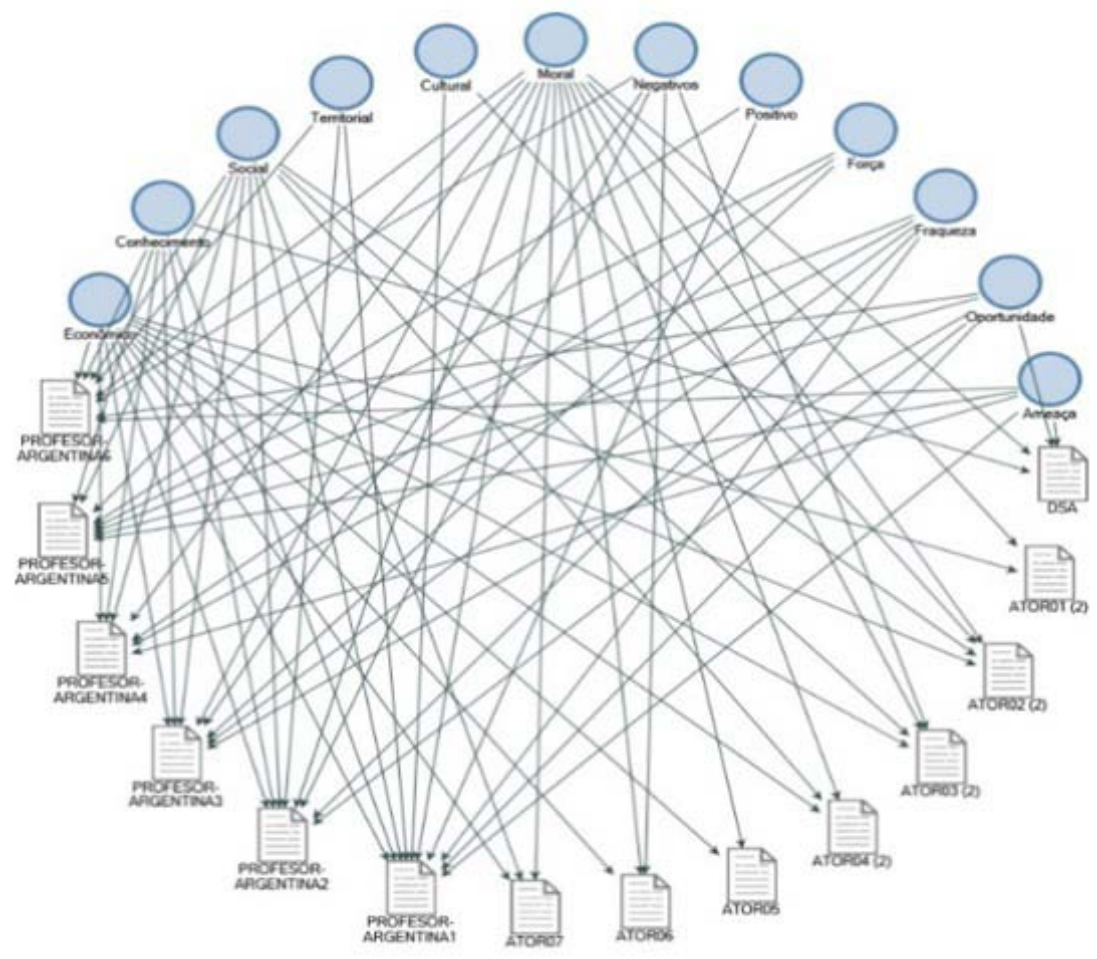

Fuente: elaboración propia utilizando Nvivo11

Las diferentes conexiones formadas entre los entrevistados y las categorías de análisis (nodos) demuestran la intensidad y frecuencia con que se codificaron las entrevistas, lo que permite deducir la validez de las categorías preestablecidas y el guion de la entrevista. Las dimensiones morales, sociales y económicas mostraron la mayor frecuencia de referencias en el análisis del contenido de las entrevistas, lo que permitió indexar los ítems como se muestra a continuación:

\section{plurais


Figura 3 Gráfico de la codificación de las entrevistas

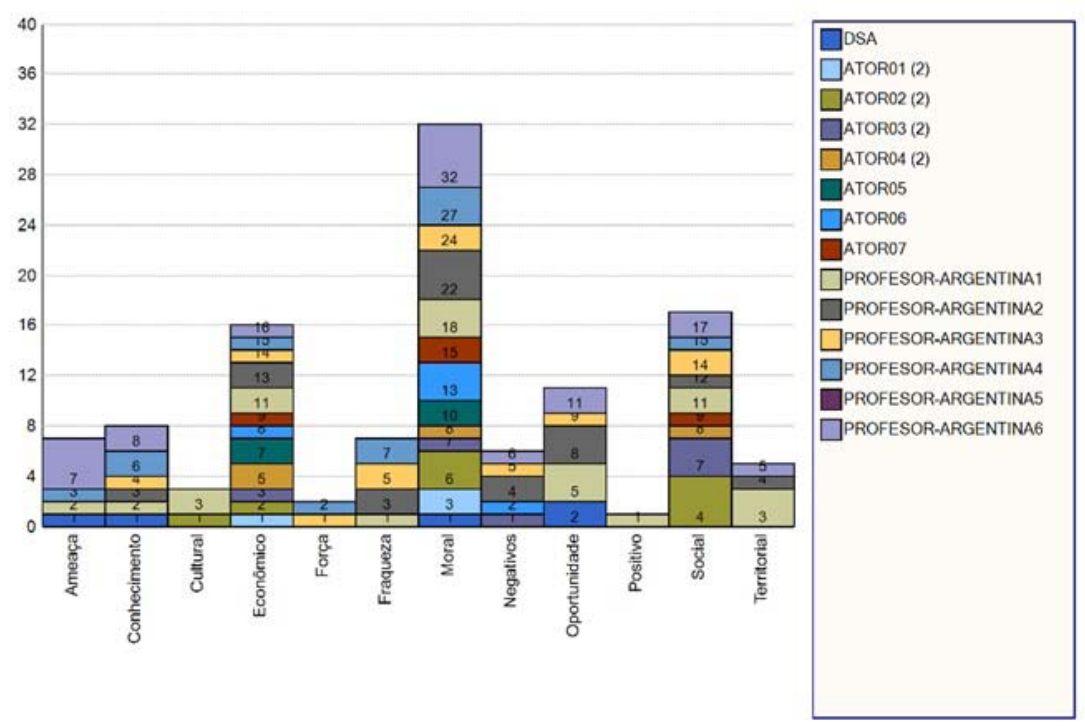

Fuente: elaboración propia utilizando Nvivo11

Los detalles del análisis siguen en la siguiente sección después de describir el caso y explicar las características principales de la universidad bajo análisis y el lugar donde se encuentra.

\section{El Estudio de Caso}

La educación adventista aparece en el mundo junto con la expansión de la denominación religiosa, como uno de los pilares de la filosofía y el mensaje adventistas, la educación tiene especial atención en esta religión. Tan importante como los proyectos misioneros, o el mensaje de salud, o las publicaciones, las escuelas mantenidas por la Iglesia Adventista del Séptimo Día (IASD) surgieron a fines del siglo XIX, como un instrumento en la preparación de misioneros y evangelistas, además de preparar a los jóvenes y a los jóvenes. niños de la iglesia dentro de los preceptos de la religión (BLANCO, 2008).

Battle Creek College en Michigan, Estados Unidos de América (EE. UU.) Fue la primera escuela adventista del mundo (1872), que años más tarde se convertiría en la primera universidad y el líder en la red, conocida hoy como Universidad Andrews, pero fue un éxito del Avondale Col-

\section{plurais}


lege, fundado en 1897, en Australia, que consolidó la expansión del modelo educativo adventista (GROSS; GROSS, 2012).

Los objetivos eran claros para la autora principal de la creación de las universidades y la principal responsable de la expansión del adventismo en el mundo, la escritora estadounidense Elena G. White (1827-1915), quien también es considerada una profetisa para los miembros de la religión: neutralizar la influencia que las escuelas públicas de los EE. UU. pudieran generar en los niños adventistas (WHITE, 2008); crear medios para que los estudiantes obtengan la salvación de sus almas a través de la educación (WHITE, 2009); y "Preparar al estudiante para el disfrute del servicio en este mundo, y para esa mayor alegría para un servicio más extendido en el mundo por venir" (WHITE, 2013, p. 13).

Estos objetivos con el establecimiento de instituciones educativas no diferían de ninguna manera de los otros colegios estadounidenses que surgieron en el siglo XVII, bajo la fuerte influencia de los estándares educativos británicos, que estaban destinados a capacitar a pastores y otros líderes de la comunidad, manteniendo su ubicación siempre en remotas ciudades y con un régimen de internado, que favoreció el aislamiento y la solidificación de los valores de una sociedad rural, con instituciones casi autosuficientes, y con la misión no solo de educar a los jóvenes intelectualmente y espiritualmente, sino de crear un fuerte sentimiento de perteneciente a una denominación religiosa (OLIVEN, 2005; LUCAS, 2010).

Basado en su propia filosofía educativa y con una estructura conservadora de valores, la educación adventista ha expandido su crecimiento aún más cada año. Ya hay más de 7.800 unidades educativas en más de 160 países en el mundo, con más de 2 millones de estudiantes matriculados desde educación infantil hasta educación superior (CASA, 2016).

En América Latina, la historia de la educación adventista se confunde con la historia de la religión en el continente. En el año 1890, una pareja misionera de los Estados Unidos de América convenció a otras tres familias alemanas para que se mudaran a Sudamérica, con el fin de evangelizar el continente. Se mudaron al estado de Entre Ríos, en el municipio de Crespo, en la República Argentina. A partir de ahí comenzó un proceso de evangelización y distribución de literatura en una comunidad fuertemente colonizada por alemanes y personas de países europeos,

\section{plurais


en 1891 otros misioneros llegaron al continente para expandir el proceso de evangelización y en 1894 llegaron de los EE. UU. el primer pastor adventista para América del Sur y en esa ciudad se organizó la primera iglesia del continente (CASA, 2016).

En 1898, siguiendo las pautas del IASD, este grupo formado por misioneros y miembros de la iglesia decidió fundar el Colegio Adventista del Plata (CAP), en una propiedad rural, que estaba entre las ciudades de Crespo y Diamante, en un pueblo llamado Camarero (Entre Ríos - Argentina). Allí, la escuela tendría las condiciones ideales, de acuerdo con el IASD, para su desarrollo, como el aislamiento de las grandes ciudades, la posibilidad de trabajo manual para los estudiantes y la ausencia de influencias urbanas. Además, según Wensell (1993, p. 66), "tenían una población adventista grande y entusiasta entre los alemanes en la región".

El sistema educativo en Argentina es marcado por una fuerte regulación estatal y una evidente preocupación con la educación pública, gratuita y accesible a toda la población. Con la reforma de la educación en 1993, fue creado el Sistema Educativo Nacional Argentino, estructurado en educación infantil, educación primaria, educación secundaria y educación superior. En los últimos años, con las consecutivas crises vividas en el país hubo un crecimiento de la participación privada en la educación del país, pero todavía sigue la educación publica como la principal en el país.

En 1908, junto al CAP, se inauguró el Sanatorio Adventista, un hospital para servir a la región y que tuvo una gran influencia en la provincia considerando que tenía médicos misioneros de origen alemán y que podían servir a la comunidad en la región. Poco a poco, muchos trabajadores comenzaron a construir sus casas en las cercanías de la escuela y el hospital, pero la administración de la escuela se mostró reacia a la posibilidad de establecer una aldea en los alrededores, sin embargo, el proceso de desarrollo era inevitable, con la presencia de una escuela y un hospital que sirvió a toda la región, en poco tiempo la aldea ya tenía sus primeros residentes, en 1966 se organizó la primera asociación de residentes de la Villa del Libertador San Martín y en 1971 se creó el municipio de Libertador San Martín (WENSELL, 1993).

En 1925, el pueblo llamado "Aldeia Camarero" llegó a ser conocido como Puiggari, una referencia a una estación de tren que existía cerca del pueblo, en la década de 1940 el pueblo tenía solo 30 casas y 180 residentes, todos vinculados a las dos organizaciones que existían allí, 
en 1954 se estableció el nombre oficial de "Villa Libertador San Martín" (STCER, 2018). El crecimiento de la aldea fue lento y controlado por los administradores de la UAP, que poseían la mayor parte de la tierra en la región, muchas familias vinculadas al IASD comenzaron a mudarse a la aldea en busca de un lugar para educar a sus hijos desde allí. comenzó a conocerse como "Colina de la Esperanza" (WENSELL, 1993).

Figura 4- Gráfico de aumento de la población en Libertador San Martín

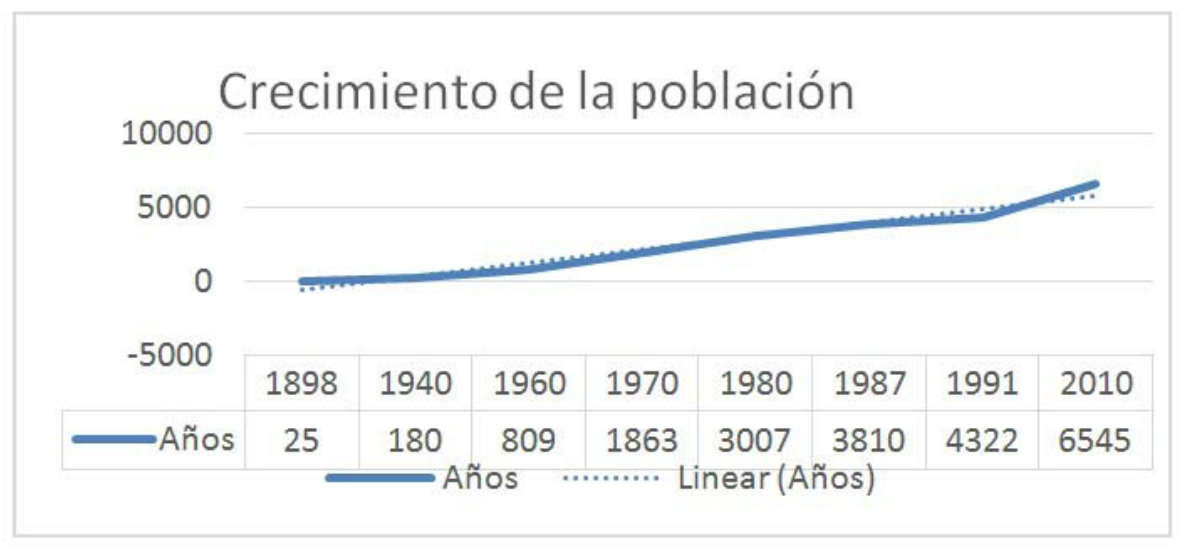

Fuente: Adaptado (LSM, 2018; STCER, 2018)

Según el censo de 2010, la población empleada de la ciudad era de 2,887 personas, el número de desempleados era de 113 personas y el número inactivo de 1944 personas (DGEC, 2010), la ciudad tiene tres cooperativas diferentes (servicios públicos, productores rural y jubilado), estación de autobuses, puesto de salud, sucursal bancaria, varios restaurantes y cafeterías, supermercados y varias empresas destinadas a servir a la población local y a los estudiantes de la región. El sector que más mueve la economía local es el inmobiliario, los alquileres tienden a costar cinco o seis veces más que en las ciudades vecinas, y el valor de la tierra también es cinco o seis veces mayor que en las ciudades vecinas. 
La región en la que se inserta la ciudad (Diamante), tiene el mayor porcentaje de personas nacidas en el extranjero en todo el estado (2.9\%). La esperanza de vida en la región es alta 74 para hombres y 81 para mujeres (DGEC, 2010), pero no es difícil ver que en la ciudad la expectativa es aún mayor. Hay muchos jubilados que transitan diariamente por la región. La ciudad tiene una estación de policía, pero los casos penales son raros y entre los residentes el sentimiento es de total confianza en el lugar, algunos entrevistados mencionaron la expresión "burbuja" para definir el lugar en relación con el resto de Argentina.

Otra característica muy particular es la presencia adventista en la política local, ya que se creó el municipio que todos los alcaldes son adventistas, algunos exprofesores o empleados de la universidad, además del "Honorable Concejo Deliberante" responsable de la legislación de la ciudad también tiene sus miembros vinculados a la religión. Algunas leyes fueron creadas debido a la presencia de la universidad y el hospital, la falta de permiso para la venta y el consumo de bebidas alcohólicas y cigarrillos en la universidad demuestran la influencia en la gobernanza del lugar.

Es importante resaltar que recién en 1990, CAP se convirtió en la Universidad Adventista del Plata (UAP), y desde 1991 comenzó sus actividades ofreciendo cursos de teología, enfermería y contabilidad, en 1994 la universidad implementó el curso de medicina. Hoy la Universidad cuenta con más de 3.400 estudiantes, inscritos en 16 cursos de educación superior, además de tener una maestría y un doctorado en teología, cursos de nivel técnico (UAP, 2017).

La institución es reconocida en el país por la calidad de su proceso educativo y por el multiculturalismo presente en la institución (CRUP, 2003), además de haber recibido el título de "universidad saludable" del gobierno de Argentina, por sus prácticas y estimular un estilo de vida. saludable (UAP, 2017).

La universidad cuenta con unos 1.100 empleados, de los cuales unos 650 trabajan a tiempo completo en la institución, que además de los departamentos universitarios tradicionales (investigación, extensión, coordinación pedagógica) tiene en su estructura una librería, radio, estudio de producción. video, secretaría de responsabilidad social y un centro universitario, que opera en el desarrollo de unidades productivas de la propia universidad, en el proceso de transferencia de tecnología y asesoramiento a empresas, incubación de nuevas empresas, integración de 
trabajos académicos y desarrollo tecnológico y un espacio para prácticas profesionales de los estudiantes (UAP, 2017).

Además del UAP, el IASD mantiene una librería, un supermercado (CEAPE), el hospital que es una de las referencias médicas y hospitalarias en Argentina, un Centro de Vida Saludable (CVS) que recibe a las personas para la recuperación de la salud a través de terapias en el mismo lugar. y una granja que produce cereales (Alimentos Granix), en todos estos espacios es posible integrarse con prácticas académicas y profesionales, $\mathrm{y}$ en muchos casos estudiantes que no pueden pagar su matrícula en estas empresas como una forma de mantenimiento de estudios.

El entrelazamiento entre el desarrollo organizacional y el desarrollo local permite a la ciudad de Libertador San Martín una particularidad en este proceso, las influencias religiosas, el intercambio de creencias y el reconocimiento de los residentes que no son practicantes de la misma religión, de la importancia de la UAP para el desarrollo, genera una visión casi uniforme de este fenómeno. El análisis de los grupos por similitud del contenido de las entrevistas demuestra esto como se muestra a continuación:

Harvey (2012) señala que las organizaciones son fuertemente responsables de construir el contexto simbólico y construir comportamientos sociales y culturales en ciertos lugares, un proceso de desarrollo guiado por una sola institución, con personas culturalmente cercanas e interesadas en los mismos objetivos, produjo un campo singular en la construcción de un "espacio de esperanza" (HARVEY, 2012). 
Figura 4 - Análisis de conglomerados por similitud de palabras (coeficiente de correlación de Pearson)

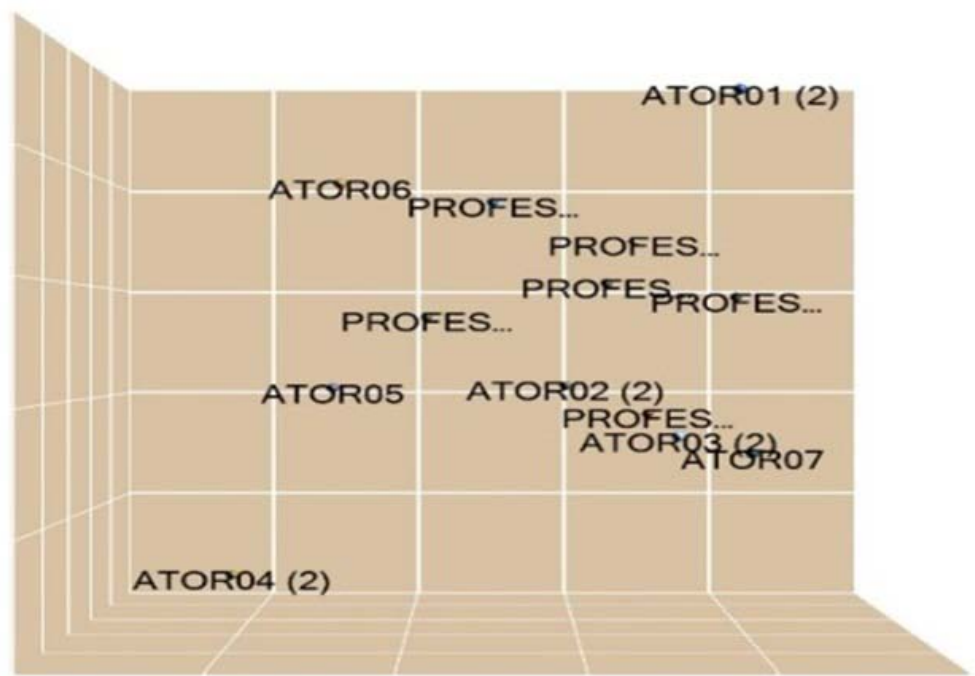

Figura 5 - Análisis de conglomerados por codificación de similitud (coeficiente Jaccard)

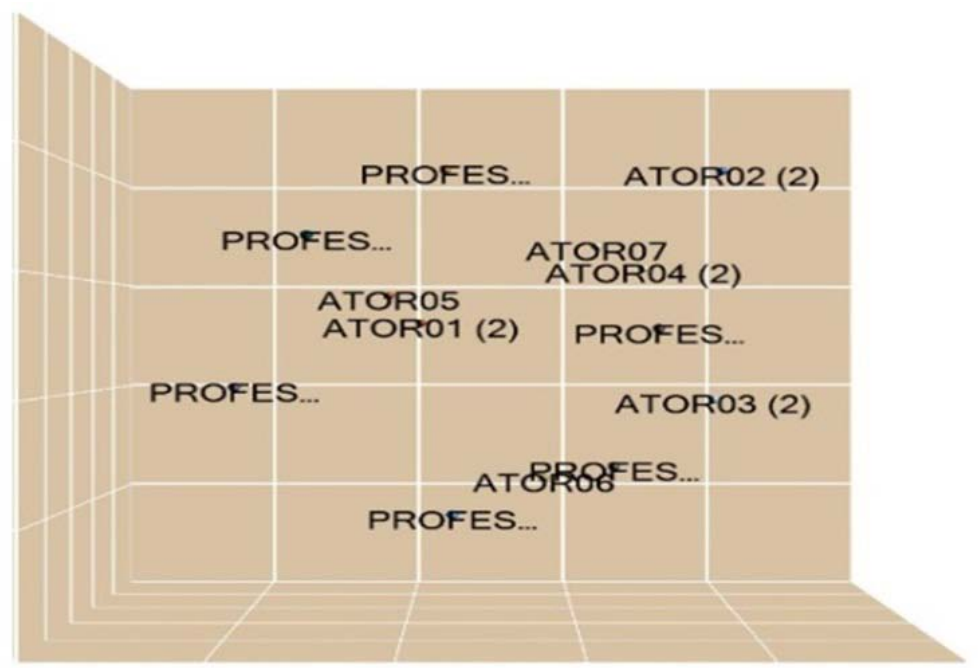


Esta fortaleza de la organización es visible principalmente cuando se analiza el contenido de las entrevistas de las expresiones de los actores sociales, tales como: "todos los que están aquí dependen de ellos, todo el comercio depende de ellos" (A1); "Mira, todo aquí gira en torno a la universidad y el hospital, sin ellos creo que esto no existiría (A3); aunque es un lugar pequeño, pero tiene muchos estudiantes (A4); Es todo para nosotros, todos están aquí por la Universidad o el Hospital, por lo que sin ellos no habría vida en esta ciudad, la ciudad ni siquiera existiría (A7).

Si solo se considera el municipio de Libertador San Martín, la UAP ya tendría una evaluación de impacto económico positiva, pero debido a que entiende que debido al tamaño de la institución, la mayoría de sus proveedores están fuera del municipio, generando la pérdida de ingresos, aun así la importancia la economía no disminuye, como dice un entrevistado: "La universidad es el mayor empleador de empleos, en todo el estado, porque tenemos más de 1100 empleados; entonces, tiene un impacto económico muy importante en la región "(PA1). Además, es importante resaltar que la aviación del impacto económico no se produce solo al verificar los consumos de la organización, sino también los generados de acuerdo con ella, con los salarios que se pagan y la presencia de personas que no estarían en el sitio si fuera no estaba allí "porque todas estas personas generan consumo. Las casas, el mercado inmobiliario, todo se mueve según las dos instituciones" (PA1).

Esta percepción del impacto económico de la universidad y sus otras empresas, por parte de los actores y gerentes sociales, es consistente con los análisis de impacto a corto plazo que se incluyen en la literatura (ELLIOTT; LEVIN; MEISEL, 1988; OCDE / IMHE, 2005; ARBO; BENNEWORTH, 2007; ROLIM; KURESKI, 2010). Sin embargo, es importante señalar que el análisis de este trabajo se limitó a evaluar el impacto de la percepción de los diferentes agentes (externos e internos) sobre los impactos económicos, debido a la falta de acceso a la información y los datos que son necesarios para la realización de los resultados. cálculos de impacto

La segunda dimensión del análisis buscó categorizar los contenidos de las entrevistas en el "nodo" del conocimiento, que se refiere a los impactos considerados a largo plazo por la presencia de instituciones educativas en el lugar (GARRIDO-YSERTE; GALLO-RIVERA, 2008). En esta dimensión de análisis, se hicieron 8 referencias en 6 de las entrevistas, todas

\author{
plurais


dentro del alcance de los gerentes de la UAP; los actores sociales no hicieron ninguna mención al respecto.

En este contexto, se destacaron dos variables: la primera con respecto al proceso de capacitación de los jóvenes que ingresan a la institución, demostrando la confianza en el proceso de enseñanza y aprendizaje que brinda la UAP "es una universidad que a pesar de estar en el campo tiene personas con una trayectoria académica muy relevante" (PA4), la segunda variable se refiere a los productos y servicios producidos por la institución, como fuente de investigación y conocimiento desarrollado por ella, está claro que estos productos fabricados aquí son únicos (...) son Algunos de los legados que tiene la universidad para la comunidad (PA1) y en la producción de investigación y extensión para la comunidad, mejorando el acervo de conocimiento de la región:

\footnotetext{
"Entonces, tenemos un proyecto que tiene un gran impacto en la comunidad, pero hay otros, junto con empresas en el campo de las ciencias económicas, y hay otros de otras áreas, como la psicología, que trabajan con escuelas, hay un libro que funciona como el Las emociones positivas de los niños, que tuvo una gran repercusión en el país y fue un libro editado, trabajó como resultado de la investigación realizada por el centro de humanidades y el curso de psicología, junto con un grupo de investigadores en el área de humanidades y trabajó con niños de los alrededores, muy necesitado Por lo tanto, este libro ha ayudado a muchos educadores en el área primaria de cómo enfrentar a estos niños, a tener la capacidad de enfrentar mejor el día a día. También en el área de teología, trabajamos constantemente con la comunidad. presencia de estudiantes en la comunidad, tanto a nivel nacional como internacional, con visitas de todo el mundo" (PA4).
}

La tercera categoría de análisis es la dimensión social, indicadores como el aumento de la población local, mejoras en el acceso a la salud, educación, movilidad urbana, índices de desarrollo humano, etc. son parte del campo de este análisis (SHIKIDA et al., 2015). En este contexto, la dimensión social fue la segunda más codificada en el análisis de las entrevistas con 17 referencias en 9 de las fuentes de la entrevista. Los principales puntos son dados a proyectos de la comunidad de la universidad, el servicio prestado por los estudiantes, la responsabilidad social de la UAP, y los valores culturales de la religión que promuevan la calidad de vida y la longevidad de las personas en la región. 
Además, la calidad de vida percibida por los actores sociales es un motivo de atractivo (GARRIDO-YSERTE; GALLO-RIVERA, 2008) para las personas que desean mejoras en sus vidas (A1, A2, A3) y no pueden ser descuidadas en el proceso de desarrollo, ampliando la discusión de preceptos exclusivamente económicos para los factores sociales (BOISER, 1996; OLIVEIRA, 2001; SACHS, 2004). Además, es importante resaltar que UAP es la principal institución de educación superior en la región de Diamante (46,361 habitantes), siendo responsable de la capacitación y accesibilidad de estos jóvenes a la educación superior.

La cuarta categoría analizada fue la dimensión territorial / ambiental que tiene un gran valor en el pensamiento sistémico del desarrollo local, teniendo en cuenta que la comprensión del espacio como un lugar multifacético y guiado por sus historicidades, complejidades y temporalidades (FISCHER, 1997; SANTOS, 1997, 2014b, a) es importante entender este proceso de formación del territorio como una ubicación atípica, debido a diferentes factores:

1. La homogeneidad de la población, el lugar fue formado principalmente por personas vinculadas a la misma creencia religiosa y con fuertes lazos de proximidad cultural, lo que favoreció el proceso de uniformidad territorial;

2. Al colonizar los lazos culturales, los misioneros evangelistas extranjeros encontraron una gran colonia alemana en la región, que favoreció el proceso de evangelización entre pares y marcó la unión según un propósito, en la creación de un "espacio de esperanza";

3. La activa participación política de los actores sociales, con el proceso de expansión de la aldea y la constitución del municipio, los residentes que ya estaban en el espacio habitado fortalecieron su influencia en torno a la legitimación del poder político, durante los casi 50 años de existencia del municipio todos los alcaldes elegidos son participantes de la misma creencia religiosa, lo que favoreció aún más el proceso de uniformidad territorial.

Este proceso de participación de la comunidad en las decisiones locales se ha observado desde la creación de la primera cooperativa en la ciudad en la década de 1950, cuyo propósito era tomar decisiones sobre los servicios públicos que se llevarían a cabo en el pueblo, así como organizar calles, servicios públicos., tomar decisiones sobre el suministro de agua, electricidad y pavimentación (WENSELL, 1993). Este proceso de participación colectiva, protagonista y

\section{plurais}


comunitaria es el requisito previo para el desarrollo del poder local (FISCHER, 1991; DOWBOR, 2016).

En este sentido, la cultura local se formó a la luz de sus pioneros "Había casi una cultura aquí hace décadas" (PA1); "Estas dos instituciones estaban formando esta comunidad, que terminó siendo un municipio y este municipio a lo largo de su historia fue dirigido por adventistas" (PA2), pero que hoy comienza un proceso de expansión que ha causado aprensión en sus miembros.

Cuadro 01. Referencias en el contenido de la entrevista para la categoría territorial/ambiental

\section{Discursos de actores y gestores sociales de la UAP}

De hecho, hay muchas familias que emigran de otras ciudades, incluso del extranjero, no solo de Argentina, que vienen a vivir aquí para educar a sus hijos, para estar un poco más cerca de ellos, para comprar sus propiedades.

Hoy podemos hablar aquí de una comunidad cosmopolita. Hubo casi una sola cultura aquí hace décadas y hoy tenemos una gran variedad. Hay descendientes de alemanes, hay latinos, hay otras regiones del país; entonces, la universidad tiene el gran desafío de poder llegar a las subculturas que tenemos en la región". "La ciudad está creciendo, no es lo mismo que hace cinco, diez años, muchas personas han venido aquí de diferentes religiones, diferentes clases y están buscando un lugar tranquilo, con la calidad de vida que tenemos aquí". "En cierto modo, el crecimiento es una preocupación, porque hoy tenemos cosas que antes no teníamos aquí, por ejemplo, antes no teníamos negocios que abrieran el sábado, pero hoy sí, porque pertenecen a personas que no guardan el sábado, por lo que es como si hubiera un conflicto ". "Entonces, creo que es uno de los aspectos negativos, (...) porque la comunidad ha crecido mucho, todavía ve un porcentaje de adventistas, pero hay personas de otras comunidades, para nuestra visión del mundo que tienen otro pensamiento". "Somos la mayoría aquí, adventistas, pero algunas cosas han cambiado hoy. Tenemos algunos negocios que abren el sábado, en el pasado, incluso aquellos que no eran de nuestra fe, pero hoy abren, porque mucha gente comprará, así que antes no teníamos tiendas de carne". , la institución fue muy fuerte en eso, hoy ya tenemos carniceros, no se trata de salvación o fe, sino de los principios de salud y las enseñanzas para una vida mejor, por lo que nos dimos cuenta de que la comunidad ha cambiado un poco más".

Fuente: Elaboración del Autor.

Esta preocupación por los cambios en la comunidad es evidente, pero muestra que los conflictos culturales son inherentes al proceso de constituir una identidad territorial (HAESBAERT, 2011), durante años fue posible mantener la hegemonía cultural, lo que benefició el proceso de 
desarrollo organizado de la comunidad. pero con la expansión del atractivo del lugar, por personas en busca de calidad de vida y un espacio en el que se configura una nueva ruralidad (CARNEIRO, 1998), con las características de una ciudad pequeño, bucólico, eminentemente rural, pero con los beneficios producidos por la evolución de los flujos de transporte y comunicación, transformando el espacio, en el que cada lugar no es solo el lugar en sí, sino las redes que se tejen en la costura sociocultural-histórica de las personas que lo habitan (SANTOS, 2014a).

Finalmente, la última categoría de análisis se ocupó de revelar los impactos del conjunto de creencias y valores organizacionales en el proceso de aculturación del lugar. En un intento por comprender la formación de una comunidad moral en torno a los principios y valores proclamados por la organización. Esta dimensión fue la más citada por los entrevistados, todos mencionaron al menos un aspecto en relación con esta dimensión y, en total, se hicieron 32 referencias codificadas en el contenido de las entrevistas.

Las palabras más citadas con significado para el análisis de la investigación fueron personas ( $1.04 \%)$, adventistas $(0.95 \%)$, estudiantes $(0.63 \%)$ y comunidad $(0.60 \%)$. La frecuencia de estas palabras indica la correlación entre el contenido analizado (Cultura) y la formación de una comunidad moral en torno a las creencias y ritos de la religión adventista.

Es posible obtener del análisis de las entrevistas que la constitución de una comunidad moral (DAVIGNON; THOMSON JR., 2015) está muy influenciada por el modelo educativo promovido por la institución y por las acciones ampliamente difundidas entre los estudiantes. Las clases de sujetos con contenido religioso, la fuerte identidad de la cultura moral y las actividades de servicio (HANSON; MOORE, 2014) se perciben fácilmente en toda la institución. Los discursos de actores sociales y gerentes están alineados para corroborar esta visión.

\footnotetext{
plurais 
Cuadro 03. Referencias en el contenido de la entrevista para la categoría territorial / ambiental

\section{Discursos de actores y gestores sociales de la UAP}

"Sí, tenemos un comportamiento diferente aquí, muchas personas preguntan por qué tenemos cosas como esta, por qué no roban, muy pocas veces hemos tenido un caso de robo, pero en otra ciudad donde trabajo, no puedes dejar cosas como las que tenemos aquí, hay muchos más casos de robo. Esto tiene una influencia de la institución".

"Entonces, además, siempre nos preocupa que estos estudiantes se comporten bien aquí, con un buen servicio de capellanía y monitoreando a los estudiantes a través de una evaluación"

"Entonces resulta que es diferente, todos son amigables, les gusta ayudar, aunque es más argentino que brasileño, creo que es cultural, de verdad. Pero creo que sí, hace la diferencia, no lo veo en Brasil o en otras ciudades aquí"

"Todo es parte de la misma iglesia y tiene su propia cultura que es buena, las cosas cierran el sábado, todo está más tranquilo aquí, esto es bueno"

"Las personas que vienen aquí las verán en la iglesia, no solo desde el punto de vista del edificio, sino que las verán rezando, participando en la obra misional, por lo que la relación es muy diferente, más ética, más honesta"

"La comunidad es muy diferente de otros lugares, mucha gente viene que no son adventistas últimamente, porque ven que este lugar es un lugar de refugio, cuando ven el nivel de tranquilidad que tenemos aquí"

"Y sí, hay mucha influencia de la iglesia, no voy a la iglesia, nunca fui, pero todos aquí van a la iglesia, creo que sí, no sé si son más éticos u honestos, porque tengo clientes que no me han pagado, ya incumplieron, no varias veces, pero a veces, así que creo que es una cuestión de carácter, educación “

"Me parece que este es un punto notable y el hecho de que se alienta al estudiante a incluir el deseo de servir y la práctica del servicio en sus prácticas profesionales"

"Entonces, el impacto es grande, porque el legado va más allá de los estudiantes. La persona que viene a vivir aquí, que ve cuáles son nuestros principios, nuestras creencias a largo plazo terminan adoptándolos, termina ... la gente no adventista se muda aquí, termina yendo a la iglesia, termina reuniéndos e adventistas

"Creo que es una fortaleza de la verdad que está en la palabra de Dios, creo que es una referencia, digamos, bíblica, moral, de formación integral de los estudiantes y reconozco en todas las reuniones que estoy con el gobierno, o con la sociedad que UAP es reconocido como un generador de profesionales con aspectos integrales, no solo profesionales técnicos, sino también valores morales"

Fuente: Elaboración del Autor. 
Indudablemente, existe una relación entre las opciones filosóficas de la institución y el comportamiento de la comunidad académica, las premisas de la pedagogía adventista se perciben fuertemente en el análisis de los planes de estudio, en las acciones de extensión y en el instituto misionero de la universidad. En varias entrevistas con gerentes de la UAP, el eslogan de la institución se presenta como un patrón de comportamiento fuertemente arraigado en la cultura organizacional "excelencia y servicio", y esta percepción se extiende a los actores sociales, que no pueden distinguir los límites de la organización educativa y religiosa, o negocios, y demostrar la fortaleza de la organización en el modelado del sitio.

En este sentido, tres aspectos parecen reforzar el esquema moral e influir en el comportamiento de la comunidad:

1. intensificación de las relaciones: teniendo en cuenta que los estudiantes, los docentes y los residentes viven en el mismo espacio, con pocas opciones de compras, socialización y movimiento, de esta manera se intensifican todas las relaciones, que Hanson y Moore (2014) clasifican como amplificadores morales;

2. la estrategia de enseñanza - como acciones deliberadas y existentes en los planes de estudio, programas y en toda la infraestructura educativa de la institución que construyen y modelan la forma de actuar y pensar y son los contornos de la cultura organizacional (HILL, 2009);

3. la práctica del servicio comunitario, constante en los programas curriculares y extracurriculares (servicios misioneros), revela un poderoso instrumento para crear una identidad de cultura moral y reforzar las enseñanzas morales (HANSON et al., 2017).

\section{Consideraciones Finales}

El propósito de este estudio fue analizar el impacto de un IES en el desarrollo de un sitio. Después de analizar el caso, fue posible verificar que la UAP y todas las organizaciones vinculadas a ella fueron los principales impulsores en la creación de la ciudad de Libertador San Martín, de esta manera su influencia en la vida cotidiana de la ciudad, en la cultura, creencias y patrones de La conducta de la ciudad es decisiva para la constitución del espacio habitado.

\section{plupais


La influencia de las organizaciones religiosas en el atractivo y la formación de las ciudades se observa a lo largo de la historia de la humanidad (ROLNIK, 2012), además del proceso de transferencia de conocimientos y recursos a través de la red que apoya a la institución, permitió organizar el territorio de Una forma distinta de otros espacios cercanos a la localidad.

Además, es importante resaltar que los impactos económicos de la institución siguen siendo decisivos para la supervivencia de la ciudad y la región, sin embargo, a través del análisis de los discursos, es posible inferir que los impactos sociales y culturales son los más observables por los entrevistados, lo que demuestra la fuerza de la organización en la representación simbólica e imaginativa de los actores sociales.

La propuesta metodológica de este trabajo no permite generalizaciones, ya que es un análisis de caso único, pero presenta fuertes indicadores de que las instituciones educativas tienen un gran poder transformador del espacio, no solo de los vectores tradicionalmente investigados (económico, educativo, conocimiento), sino también a través de la movilización de la población, la participación en estructuras de gobernanza, mecanismos que inducen el atractivo del lugar, organizador del espacio habitado y productor de patrones culturales.

En cuanto a la dimensión cultural, se observó que la estructura educativa de la institución educativa influye en el comportamiento moral de la comunidad, todos los mecanismos creados, las actividades de servicio, la identidad de la cultura y el refuerzo moral diario, se perciben como formadores del comportamiento moral. Por supuesto, estos no son los únicos factores que influirán en el comportamiento ético y moral del individuo (KOHLBERG; HERSH, 1977), pero son efectivos cuando se presentan en el contexto de una institución educativa confesional considerada conservadora y que tiene su refuerzo en los miembros que conforman la comunidad.

Finalmente, es importante resaltar que la "colina de la esperanza" como un espacio para la producción organizacional funcionó como un "espacio de la esperanza" (HARVEY, 2012) para los miembros de la religión o como una "ciudad de llegada" (SAUNDERS, 2013), para aquellos que buscan calidad de vida, armonía y el clima bucólico de la ruralidad allí, pero el proceso de expansión y crecimiento de la ciudad, la llegada de nuevas culturas y el desarrollo de la región exigirán aún más participación de la universidad en el proyecto político de la región. , en la bús- 
queda de cohesión social, acogiendo nuevas culturas y especialmente el desarrollo del poder local, que está interesado en servir no solo los intereses de los miembros de la misma cultura, sino también las diferentes personas que se unen a este territorio.

\section{REFERÊNCIAS}

ARBO, P.; Benneworth, P. Understanding the Regional Contribution of Higher Education Institutions: A Literature Review. Paris: OECD Publishing, 2007.

BARDIN, L. . Análise de Conteúdo. 1ª ed. São Paulo: Edições 70, 2011.

BLACKWELL, Melanie; Cobb, Steven; Weinberg, David. The Economic Impact of Educational Institutions: Issues and Methodology. Economic Development Quarterly, v. 16, n. 1. p. 88-95, 2002 .

BLUESTONE, Barry. UMASS/Boston: An Economic Impact Analysis. University of Massachusett, 1993.

BOISER, Sergio. Em busca do esquivo desenvolvimento regional entre a caixa-preta eo projeto político. Planejamento e Políticas Públicas, n. 13. p. 37, 1996.

BOURDIEU, Pierre. A economia das trocas simbólicas. $8^{\circ}$ ed. São Paulo: Perspectiva, 2015.

Carneiro, Maria José. Ruralidade: novas identidades em construção. Estudos Sociedade e Agricultura, v. 11. p. 58-75, 1998.

CASA. Casa Publicadora Brasileira, 2016. Disponível em: http://www.educacaoadventista.org.br. Acesso em: 29 de janeiro de 2016.

CRESWELL, J. W. . Projeto de Pesquisa: métodos qualitativo, quantitativo e misto. $3^{\text {a }}$ ed. Porto Alegre: Artmed, 2010.

CRUP. Consejo de Rectores de Universidades Privadas. Historia de lãs Universidades Argentinas de Gestion Privada. 45 Aniversario. Buenos Aires: Editora Dunken, 2003.

DAVIGNON, Phil; THOMSON Jr., ROBERT A. Christian. Colleges and Universities as Moral Communities: The Effects of Institutional Characteristics on Student Religiosity. Religious Research Association, March 24. p. 531-554, 2015.

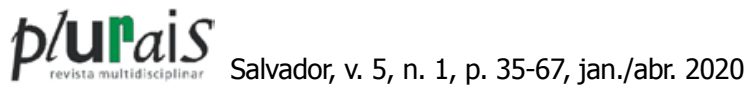


DGEC, Direcion General de Estadísticas y Censos. Censo, 2010. Disponível em: $<$ https://www. entrerios.gov.ar/dgec/buscador-cuadros-censo-2010/>. Acesso em: 29/01/2018.

Dowbor, Ladislau. O que é poder Local? Imperatriz (MA): Ética, 2016.

DSA. Pedagogia Adventista. $2^{\circ}$ ed. Tatui - SP: Casa Publicadora Brasileira, 2009.

DURKHEIM, Émile. As formas elementares da vida religiosa: o sistema totêmico na Austrália. São Paulo: Martins Fontes, 1996.

ELLIOTT, Donald S.; LEVIN, Stanford L.; MEISEL, John B. Measuring the economic impact of institutions of higher education. Research in Higher Education, v. 28, n. 1. p. 17-33, 1988.

ETZKOWITZ, H.; LEYDESDORFF, L. Universities in the Global Knowledge Economy: A Triple Helix of Academic-Industry-Government Relations. Londres: Cassell, 1997.

FISCHER, Tania. D. Poder local no Brasil: temas de pesquisas e desafios da transição. Revista de Administração Pública, v. 25, n. 2, 1991.

A cidade como teia organizacional: inovações, continuidades e ressonâncias culturais

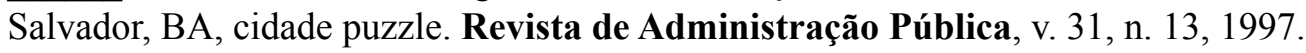

FURTADO, Celso. A Nova Dependência. São Paulo: Paz e Terra, 1982.

GARRIDO-YSERTE, Rubén; GALLO-RIVERA, María Teresa. The impact of the university upon local economy: three methods to estimate demand-side effects. The Annals of Regional Science. p. 39-67.

GOULART, Sueli; VIEIRA, Marcelo Milano Falcão. Science \& Technology, Development and Local Power: Elements for Analysis of the Brazilian Context. Journal of Technology Management \& Innovation, v. 2, n. 1. p. 64-71, 2007.

Desenvolvimento e organizações: as universidades como eixo de articulação entre o local e o global. O\&S, v. 15, n. 45, abr/jun 2008. p. 91-107, 2008.

GROSS, Renato; GROSS, Janine S. Filosofia da educação Cristã: Uma abordagem adventista. Tatui - SP: Casa Publicadora Brasileira - CPB, 2012.

HAESBAERT, Rogério. Da desterritorialização à multiterritorialidade. X Encontro de Geógrafos da América Latina Universidade de São Paulo. p. 15, 2005. 
. edição, $6^{\mathrm{a}}$. O mito da desterritorialização: "do fim dos territórios" as multiterritorialidades. Rio de Janeiro: Bertrand Brasil, 2011.

HANSON, William R.; Moore, Jeffrey R. Business Student Moral Influencers: Unseen Opportunities for Development? Academy of Management Learning \& Education, v. 13, n. 4, December 1, 2014. p. 525-546, 2014.

HANSON, William R. et al. Theory of Moral Development of Business Students: Case Studies in Brazil, North America, and Morocco. Academy of Management Learning \& Education, v. 16, n. 3, September 1, 2017. p. 393-414, 2017.

HARVEY, D. Espaços de Esperança. Tradução de Gonçalves, Adail Ubirajara Sobral and Maria Stela. $5^{\text {a }}$ ed. São Paulo: Edições Loyola, 2012.

HILL, Jonathan P. Higher Education as Moral Community: Institutional Influences on Religious Participation During College. Journal for the Scientific Study of Religion, v. 48, n. 3. p. 515534, 2009.

KOHLBERG, Lawrence; HERSH, Richard H. Moral Development: A Review of the Theory. Theory Into Practice, v. 16, n. 2. p. 53-59, 1977.

Lester, Richard K.; Sotarauta, Markku. Innovation, Universities, and the Competitiveness of Regions. Helsinki: Tekes, 2007.

LOPES, Roberto Paulo Machado. Universidade Pública e Desenvolvimento Local: uma abordagem a partir dos gastos da Universidade Estadual do Sudoeste da Bahia. 2001 (Mestrado) Escola de Economia, Universidade Federeal da Bahia, Salvador, 2001.

. Universidade, Externalidades e Desenvolvimento regional: as dimensões socioeconomicas da expansão do ensino superior em Vitória da Conquista. 2012. 360 f (Doutorado) Faculdade de Geografia e História, Universidade de Barcelona, Barcelona, 2012.

LSM, Municipio de Libertador San Martin. Municipio, 2018. Disponível em: $<$ http://munlsanmartin.gov.ar/?q=municipio $>$. Acesso em: 29/01/2018.

LUCAS, Christhopher J. La Educación Superior Norteamericana: Una historia. Buenos Aires: Universidad de Palermo, Vol. 2, 2010.

MADER, Marlene et al. Monitoring networking between higher education institutions and regional actors. Journal of Cleaner Production, v. 49. p. 105-113, 2013. 
MADOERY, Oscar. Los desarrollos latinoamericanos y sus controversias. $1^{\text {a }}$ ed. Ushuaia: Ediciones UNTDF, 2016.

OCDE/IMHE. Supporting the Contribution of Higher Education Institutions to Regional Development. OECD Publishing. p. 1-28, 2005.

OLIVEIRA, F. D. Aproximações ao enigma: o que quer dizer desenvolvimento local? . São Paulo: Pólis, 2001.

OLIVEN, Arabela Campos. A marca de origem: comparando colleges norte-americanos e faculdades brasileiras. Cad. Pesqui., v. 35, n. 125. p. 111-135, 2005.

PASTOR, José Manuel; PÉREZ, Francisco; GUEVARA, Juan Fernández de. Measuring the local economic impact of universities: an approach that considers uncertainty. High Education, n. 65. p. 539-564, 2013.

ROLIM, Cássio; SERRA, Maurício. Instituições de Ensino Superior e Desenvolvimento Regional: O Caso da Região Norte do Paraná. Revista de Economia, v. 35, n. n. 3 (ano 33). p. 16, 2009.

ROLIM, Cássio; KURESKI, Ricardo. O Impacto Econômico de curto-prazo das universidades estaduais Paranaenses. In. Universidade e Desenvolvimento Regional: o apoio das instituições de ensino superior ao desenvolvimento regional. Curitiba: Juruá, 2010.

ROLIM, Cássio; SERRA, Maurício. Universidade e desenvolvimento Ser da região X estar na região. 7. ${ }^{\circ}$ CONGRESSO IBÉRICO DE ESTUDOS AFRICANOS, Lisboa. p. 21, 2010.

ROLIM, Cássio; SERRA, Mauricio; BASTOS, Ana Paula V. Changing Brazilian Higher Education Institutions Towards the Third Mission The Case of Two Brazilian Universities. EAIR 36th Annual Forum in Essen, Germany, 2014.

ROLNIK, Raquel. O que é cidade. São Paulo: Brasiliense, 2012.

RUSS, Daniel; SARGENT, Mark L. Moral Imagination at a Christian Institution. In: Henry, Douglas V.; Beanty, Michael D. Christianity and the Soul of the University. United States of America: Baker Publishing Group, 2006.

SACHS, Ignacy. Desenvolvimento: Includente, sustentável, sustentado. Rio de Janeiro: Garamond, 2004. 
SANTOS, Milton. Técnica, Espaço, Tempo: Globalização e meio técnico científico informacional. $3^{\circ}$ ed. São Paulo: Editora Hucitec, 1997.

Metamorfoses do Espaço Habitado: Fundamentos Teóricos e Metodológicos da Geografia. $6^{\circ}$ ed. São Paulo: Edusp, 2014a. $2014 \mathrm{~b}$.

A natureza do espaço: Técnica e Tempo, Razão e Emoção. $4^{\circ}$ ed. São Paulo: Edusp,

SAUNDERS, Doug. Cidade de Chegada: a migração final e o futuro do mundo. Tradução de Groupp, Sieben. São Paulo: DVS, 2013.

SEN, Amartya. Desenvolvimento como Liberdade. $8^{\circ}$ impressão: Compahia das Letras, 1999.

SHIKIDA, Perry Francisco Assis et al. A importância das Universidades estaduais no desenvolvimento econômico dos municípios do Paraná: Análise dos efeitos de mèdio e longo prazo. In. As universidades estaduais e o desenvolvimento do Paraná. Ponta Grossa: UEPG. p. 75-114, 2015 .

SIQUEIRA, Fabiane J. S.; FERRAZ, Marcelo I. F. A UESC e seus efeitos para o desenvolvimento regional. Reflexões Econômicas, v. 1, n. 2. p. 86-104, 2016.

STCER, Secretaria de Turismo y Cultura de Entre Ríos. Libertador General San Martin, 2018. Disponível em: $<$ http://www.unatierradiferente.com/destinos/libertador-general-san-martin.htm $>$. Acesso em: 29/01/2018.

SUÁREZ, Adolfo S. Redenção, liberdade e serviço: os fundamentos da pedagogia de Ellen G. White. $1^{\circ}$ ed. Engenheiro Coelho, SP: UNASPRESS, 2010.

SUPRIYADI, R. Ery. Local Economic Development And Triple Helix: Lesson Learned From Role of Universities In Higher Education Town of Jatinangor, West Java, Indonesia. Procedia Social and Behavioral Sciences, v. 52. p. 299-306, 2012.

UAP. Universidad Adventista Del Plata, 2017. Disponível em: $<$ http://www.uap.edu.ar/institucional/nuestra-historia/>. Acesso em: 15 de dezembro de 2017.

VASCONCELOS, Eduardo Mourão. Complexidade e Pesquisa Interdisciplinar: Epistemologia e Metodologia Operativa. $3^{\circ}$ ed. Petrópolis, RJ: Editora Vozes, 2007.

WEBER, Max. A ética protestante e o espírito do capitalismo. Tradução de Smrecsányl, M. Irene de Q. F.; Smrecsányl, Tamás J. K. M. São Paulo: Pioneira, 1999. 
WENSELL, Egil H. El poder de uma Esperanza: que educa y sana. 1 ed. Libertador San Martin: Universidade Adventista Del Plata UAP, 1993.

WHITE, Ellen G. Fundamentos da educação cristã: a família, a escola e a comunidade no contexto da aprendizagem. Tatuí - SP: Casa Publicadora Brasileira, 2008.

Conselhos sobre educação. 3. ed. Tatuí - SP: Casa Publicadora Brasileira, 2009.

. Educação. 9. ed. Tatuí - SP: Casa Publicadora Brasileira, 2013.

YIN, R. K. . Estudo de caso: planejamento e métodos. $3^{\circ}$. Porto Alegre: Bookman, 2005.

ZAPATA, Tânia. Desenvolvimento Territorial à distância. Florianópolis: SEaD/UFSC, 2007. $153 \mathrm{p}$.

Recebido em: 10 de abril de 2020

Inserido em: 20 de maio de 2020

Esta obra está licenciada com uma Licença Creative Commons Atribuicão 4.0 Internacional. 